\section{Eosinophilic Esophagitis Is Probably a Comorbid Condition in Egg-Allergic Patients Undergoing Egg Oral Immunotherapy}

García Rodríguez R, Morano Lozano L, Extremera Ortega A, Gonzalez Jiménez OM, Borja Segade J, Gomez Torrijos E Department of Allergy, Hospital General Universitario de Ciudad Real, Ciudad Real, Spain

J Investig Allergol Clin Immunol 2020; Vol. 30(1): 60-61 doi: $10.18176 /$ jiaci.0438

Key words: Eosinophilic esophagitis. Oral immunotherapy. Egg allergy. Comorbidity. Adverse reactions.

Palabras clave: Esofagitis eosinofílica. Inmunoterapia oral. Alergia al huevo. Comorbilidad. Reacciones adversas.

Oral immunotherapy (OIT) with food is effective for raising the threshold of reactivity in allergic children. However, its safety is of some concern, since it is associated with an increased risk of mild and moderate reactions [1], especially during the induction phase and the first months of the maintenance phase.

Recent reports of eosinophilic esophagitis (EoE) in patients undergoing OIT indicate that the disease might be a late complication of the procedure.

In 2014, Lucendo et al [2] published a meta-analysis on the evidence for the association between EoE and OIT. A total of 12 studies including patients undergoing OIT were analyzed. Twenty patients were diagnosed with EoE: 3 were individual cases, and the remainder were part of case series. Taking into account only the 17 cases of EoE in the case series, EoE was diagnosed in $2.4 \%$ of the patients undergoing OIT. Milk was the most frequently implicated food ( 9 patients, $52.9 \%$ ), followed by peanut (7 patients, $41.2 \%$ ) and egg (1 patient, $5.8 \%$ ).

Two case series have been reported since the publication of the meta-analysis. One included 57 children undergoing milk OIT; EoE was diagnosed in 3 patients (5.3\%) [3], all of whom achieved remission after a milk avoidance diet. The other series [4] consisted of 128 children undergoing OIT with milk or egg; $6(4.7 \%)$ developed EoE (5 while on milk OIT and 1 while on egg OIT). In 1 patient, esophageal disease remitted after a milk-free diet, although the other 5 patients were treated with proton pump inhibitors (PPIs) or swallowed topical-acting corticosteroids; therefore, it could not be determined which was the responsible food in these patients.

Milk seems likely to be involved in EoE diagnosed during OIT, although there are no studies that suggest this same causal relationship in patients undergoing egg OIT, in which the risk of EoE is very low [5].

The aim of this study was to determine the frequency with which EoE is diagnosed in patients undergoing egg OIT and to determine the role of egg in EoE in these patients.

We performed a prospective, observational study of patients aged $<15$ years who were diagnosed with IgE- mediated egg allergy. The patients subsequently underwent OIT and were diagnosed with EoE during the maintenance phase of the procedure (when they ate 1 cooked egg 3 times a week). The diagnosis was made after performing an endoscopic biopsy of the esophagus ( $>15$ eosinophils/hpf). Patients were initially offered high doses of PPIs for 8 weeks. An egg-free diet was proposed in nonresponders, and esophagoscopy was repeated after 6 weeks. If remission was not achieved, a 6-food diet was offered, with sequential reintroduction of each food every 6 weeks until the food responsible was determined.

The parents or guardians signed an informed consent document.

Of the 90 patients who underwent egg OIT, 3 were diagnosed with EoE (3.3\%). Two patients had severe egg allergy, and 1 was treated with omalizumab for moderatepersistent allergic asthma.

The 3 patients were diagnosed with EoE between 2.5 and 4.5 years after starting egg OIT and while they were regularly eating egg. Only 1 of the 3 patients responded to high doses of PPIs, although she developed esophageal candidiasis, and the treatment was withdrawn. None of the 3 responded to an egg-free diet, and only 1 completed the 6-food elimination diet; in this case, milk was the trigger of EoE. This patient currently takes pasteurized egg white in low doses ( $3 \mathrm{~mL}$ on 3 days a week) and follows a milk-free diet, thus maintaining EoE in remission.

In the other 2 cases, the food that caused esophageal disease is unknown. The patients were treated with swallowed topicalacting corticosteroids, and both are currently in remission.

The results of this study show that egg was not responsible or, at least, was not the only food responsible for EoE in any of the patients diagnosed with EoE during the maintenance phase of egg OIT.

In 1 patient, milk triggered EoE. In the other 2 cases, the food trigger could not be determined, because the patients did not complete the elimination diet.

The frequency of EoE diagnosed during the maintenance phase of OIT in our series is similar to that of other published studies $[2,4]$ and lower than that described with milk [3].

A recent study evaluated 12083 food-allergic children, of whom 570 were diagnosed with EoE, ie, $4.7 \%$ of those who were allergic to food developed EoE without being on OIT [5]. This suggests that the prevalence of EoE in candidates for OIT is similar to that of the population actually undergoing OIT. Therefore, OIT would not be a risk factor for developing EoE.

In most studies, milk is the food most frequently responsible for EoE [6], followed by cereals and eggs, thus explaining why EoE is diagnosed more frequently in patients undergoing OIT with milk [1]. Consequently, EoE that is diagnosed during food OIT has similar characteristics to that which occurs in food-allergic patients who are not undergoing food OIT (eg, most frequently involved food).

Isolated cases of EoE reported in patients desensitized with food [8-9] may have influenced the perception that OIT increases the risk of EoE caused by the food involved.

Our results indicate that EoE diagnosed during OIT with egg seems more a comorbidity than a complication of the procedure. Similar observations may be made with other foods, although more studies with larger case series and other foods are needed to confirm this hypothesis. 


\section{Funding}

The authors declare that no funding was received for the present study.

\section{Conflicts of Interest}

The authors declare that they have no conflicts of interest.

\section{Previous Presentations}

This study was presented as an oral communication in the XXXI Congress of the SEAIC (Valencia, Spain, 2018).

\section{References}

1. Nurmatov U, Dhami S, Arasi S, Pajno GB, Fernandez-Rivas M, Muraro $A$, et al. Allergen immunotherapy for IgE-mediated food allergy: a systematic review and meta-analysis. Allergy. 2017;72:1133-47.

2. Lucendo AJ, Arias A, Tenias JM. Relation between eosinophilic esophagitis and oral immunotherapy for food allergy: a systematic review with meta-analysis. Ann Allergy Asthma Immunol. 2014;113:624-29.

3. Gómez Torrijos E, Mendez Díaz Y, Moreno Lozano L, Extremera Ortega AM, Borja Segade J, Feo Brito JF, et al. Frequency and Course of Eosinophilic Esophagitis During Oral immunotherapy for Cow's Milk Allergy in a Series of 57 Children. J Investig Allergol Clin Immunol. 2017;27:127-50.

4. Echeverría-Zudaire LA, Fernández-Fernández S, Rayo-Fernández A, Muñoz Archidona C, Checa-Rodríguez R. Primary eosinophilic gastrointestinal disorders in children who have received food oral immunotherapy Allergol Immunopathol (Madr). 2016;44:531-6.

5. Graham F, Tardio N, Paradis L, Des Roches A, Bégin P. Update on oral immunotherapy for egg allergy. Hum Vaccin Immunother 2017;13: 2452-61.

6. Molina-Infante J, Lucendo AJ. Letter: dietary therapy in eosinophilic oesophagitis- do not test, just eliminate and reintroduce the most common food triggers. Aliment Pharmacol Ther. 2016;44:904-5.

7. Hill DA, Dudley JW, Spergel JM. The prevalence of eosinophilic esophagitis in pediatric patients with IgE-mediated food allergy. J Allergy Clin Immunol Prac. 2017:5:369-75.

8. Morais Silva P, Antunes J, Chambel M, Prates S, Leiria Pinto P. Diagnosis of eosinophilic esophagitis in an infant undergoing milk oral immunotherapy- a case report. Eur Ann Allergy Clin Immunol. 2014;46:154-6

9. Garcia Rodriguez R, Mendez Días Y, Moreno Lozano L, Extremera Ortega A, Gomez Torrijos E. Eosinophilic Esophagitis After Egg Oral Immunotherapy in an Adult With Egg-Allergy and Egg-Bird Syndrome. J Investig Allergol Clin Immunol. 2017;27:266-7.

Manuscript received July 4, 2019; accepted for publication July 24, 2019.

Rosa García Rodríguez Hospital General Universitario de Ciudad Real Calle Obispo Rafael Torija s/n 13005 Ciudad Real, Spain E-mail: rosag@sescam.org 